\title{
Synthesis of Magnetite-Containing Polyaniline- Polyacrylamide Nanocomposite, Characterization and Corrosion Inhibition Behavior on Mild Steel in Acid Media
}

\author{
R. GEETHANJALI and S. SUBHASHINI
}

Department of Chemistry, Avinashilingam Institute for Home Science and Higher Education for Women, Coimbatore 641043, India

anjalirajj@gmail.com

Received 4 January 2013 / Accepted 14 February 2013

\begin{abstract}
A novel method for synthesizing magnetite-containing polyaniline-polyacrylamide nanocomposite (PAni-PAAm/ $/ \mathrm{Fe}_{3} \mathrm{O}_{4}$ ) nanocomposite has been reported. The synthesized polymer was characterized with Fourier transform infrared spectroscopy (FTIR) and size of the polymer particles was determined using particle analyzer. The corrosion inhibition action of the polymer nanocomposite has been investigated using weight loss measurements, Tafel polarization and electrochemical impedance spectroscopic techniques. The experimental results obtained revealed that the synthesized polymer inhibits the mild steel corrosion in $\mathrm{HCl}$ medium and maximum efficiency was obtained at $100 \mathrm{ppm}$ concentration of the inhibitor. Potentiodynamic polarization studies clearly showed that the PAni-PAAm/ $/ \mathrm{Fe}_{3} \mathrm{O}_{4}$ acted as mixed inhibitor. Adsorption of the inhibitor on the metal surface obeyed Langmuir adsorption isotherm.
\end{abstract}

Keywords: Polyaniline, Polyacrylamide, Nanocomposite, Corrosion inhibitor

\section{Introduction}

Polymerization of monomers having different properties and reaction conditions is a challenging venture, because such monomers have low compatibility and usually form two phases in a reaction system ${ }^{1}$. Very few papers are published based on copolymerization of aniline with vinyl compounds like vinyl acetate ${ }^{2}$, acrylonitrile $e^{3-5}$ and styrene ${ }^{6}$, in the presence of various surfactants using $\mathrm{KIO}_{3}$ as oxidant. Hence polymerization of aniline with vinyl monomers is of interest.

Metal-polymer nanocomposite has gained considerable attention in various fields like corrosion inhibition coatings, industrial applications, electrical and electronic fields. Nanoparticles of zinc oxide ${ }^{7}$, titania $^{8}$, alumina ${ }^{9}$, calcium carbonate ${ }^{10}$, layered silicates ${ }^{11}$, multiwalled carbon nanotubes ${ }^{12}$ and zirconia $^{13}$ have been incorporated in polymers like polyaniline, polypyrrole, polyvinyl acetate, alkyd resin, epoxy resin etc. and used as corrosion resistant coatings. Among them magnetite-incorporated copolymers were reported for potential uses in the fields of controlled drug delivery, biosensors, batteries, display devices and corrosion inhibitive coatings. The magnetite nanoparticles also improve the 
properties of polymers such as compatibility with organic molecules and resistance to leaching ${ }^{14}$. In this investigation we have reported a novel method for synthesizing $\mathrm{Fe}_{3} \mathrm{O}_{4}$ /polyaniline-polyacrylamide nanocomposite (PAni-PAAm/ $/ \mathrm{Fe}_{3} \mathrm{O}_{4}$ ) in ethanol-water medium. The magnetite/polymer nanocomposites are usually used in the form of coatings. In the present work the magnetite/polymer nanocomposites are used as inhibitors by making it soluble in the acid medium as well as in water by sonication.

\section{Experimental}

Aniline (Reachem) was distilled and stored in dark at room temperature. Acrylamide (Lobachemie) and ammonium persulphate (Merck), $\mathrm{FeCl}_{3}$ (Sd fine), $\mathrm{FeSO}_{4}$ (spectrum), ammonium hydroxide and ethanol were used without further purification. Distilled water was used for polymerization.

\section{Preparation of magnetite nanoparticles}

The magnetite nanoparticles were prepared by oxidative chemical co-precipitation method ${ }^{15}$. $0.5 \mathrm{M} \mathrm{FeCl}_{3}$ and $0.5 \mathrm{M} \mathrm{FeSO}_{4}$ was taken in a ratio of $1: 1.75$ and mixed thoroughly in a round bottomed flask under nitrogen atmosphere. The solution was stirred with a magnetic stirrer, while $9 \mathrm{~mL}$ of ammonium hydroxide was quickly charged into the solution. Black precipitate of magnetite nanoparticles were obtained, consequently $\mathrm{pH}$ of the solution was adjusted to 9 by adding excess of ammonium hydroxide. After 2 hours of stirring, the magnetite nanoparticles were centrifuged and dried in an oven for 2 hours.

\section{Synthesis of magnetite/polyaniline-polyacrylamide nanocomposite}

The obtained magnetite nanoparticles $(100 \mathrm{mg})$ were dispersed in ethanol/water $(40 \mathrm{~mL}: 60 \mathrm{~mL})$ uniformly by sonicating for about half an hour. The solution was purged with nitrogen for 15 minutes to eliminate the oxygen present in the medium. Distilled aniline and acrylamide (1:1 ratio) was added to the solution, followed by added ammonium persulphate (20 mL:1 M) in drops for 15 minutes under nitrogen purge. The whole reaction system was maintained at $10{ }^{\circ} \mathrm{C}$ in an ice bath. The reaction was continued for 3 hours with constant stirring in a magnetic stirrer. The obtained polymer solution was refrigerated for 24 hours. The resulting colloidal black precipitate was collected by centrifugation and dried in an oven for half an hour and subjected to further characterization and corrosion studies.

\section{Characterization and Corrosion inhibition studies}

\section{FTIR Spectroscopy}

To confirm the formation of $\mathrm{Fe}_{3} \mathrm{O}_{4}-\mathrm{PAni}$ and $\mathrm{Fe}_{3} \mathrm{O}_{4}$-PAAm nanoparticles during polymerization, FTIR of the prepared nanoparticles was evaluated in the scan range of $4000-400 \mathrm{~cm}^{-1}$, using Bruker Tensor 27 FTIR Spectrometer.

\section{Particle size analysis}

The average diameter range of the nanoparticles of the polymer nanocomposite was analyzed using Horiba Scientific nanoparticle analyzer SZ 100.

\section{Corrosion protection efficiency measurements}

The weighed mild steel coupons $(5 \mathrm{~cm} \times 1 \mathrm{~cm})$ in triplicate were placed in $\mathrm{HCl}$ containing various concentrations of the inhibitor. Inhibition efficiency, surface coverage and corrosion rate were calculated using the following formulae.

$$
\text { Inhibition efficiency }(\mathrm{IE} \%)=\frac{\mathrm{W}_{0}-\mathrm{W}_{\mathrm{i}}}{\mathrm{W}_{0}} \times 100
$$




$$
\begin{aligned}
\text { Corrosion rate }=\mathrm{Cr}(\mathrm{mpy}) & =\frac{87.6 \times \mathrm{W}}{\text { A.t.D }} \\
\text { Surface coverage }(\theta) & =\frac{\mathrm{W}_{0}-\mathrm{W}_{\mathrm{i}}}{\mathrm{W}_{0}}
\end{aligned}
$$

Where, Wo is the weight loss without inhibitor, $W i$ is the weight loss with inhibitor, $W$ is the weight of the mild steel sample (all weights in $\mathrm{g}$ ), $A$ is the area of the mild steel sample in $\mathrm{cm}^{2}, t$ is the time of exposure of metal sample in hours, $D$ is the density of the mild steel $\left(7.86 \mathrm{gcm}^{3}\right)$ and $\theta$ is the surface coverage.

The weight loss studies were carried out at room temperature for different time intervals and at different temperatures (303-353 K) each for a period of half-an hour. The weight loss data were used to calculate the corrosion rate and inhibition efficiency.

\section{Electrochemical corrosion measurements}

The electrochemical experiments were carried out using a three electrode cell having mild steel (surface area: $\left.1 \mathrm{~cm}^{2}\right)$ as working electrode, a saturated calomel electrode $\left(\mathrm{Hg} / \mathrm{Hg}_{2} \mathrm{Cl}_{2} / \mathrm{sat}\right.$ $\mathrm{KCl})$ as reference electrode and platinum electrode as counter electrode. The metal surface was polished well with silicon carbide paper (No.400) before use. The electrolyte used was acidic solution with different concentration of the inhibitor at $30{ }^{\circ} \mathrm{C}$. Potentiodynamic polarization and impedance studies were conducted and the inhibition efficiency of the synthesized polymer inhibitor was calculated.

\section{Results and Discussion Characterization FTIR analysis}

The FTIR spectrum of PAni-PAAm is shown in Figure 1. The characteristic benzenoid and quinonoid bands of polyaniline appear at $1580 \mathrm{~cm}^{-1}$ and $1512 \mathrm{~cm}^{-1}$. The absorption of 1,4 substituted phenyl ring, and aromatic $\mathrm{C}-\mathrm{H}$ bending might have been overlapped and appears as a peak at $852 \mathrm{~cm}^{-1}$. The band at $1300 \mathrm{~cm}^{-1}$ is due to NH bending vibration, while peak at $1096 \mathrm{~cm}^{-1}$ proves the presence of protonated $\mathrm{PAni}^{3}$. The band at $2835 \mathrm{~cm}^{-1}$ could be attributed to aliphatic $\mathrm{CH}$ stretching vibrations of polyacrylamide. The absorptions at $1157 \mathrm{~cm}^{-1}$ and $754 \mathrm{~cm}^{-1}$ corresponding to in-plane and out-of-plane $-\mathrm{CH}$ confirms the presence of polyacrylamide.We know that the amide absorbs at $1640-1680 \mathrm{~cm}^{-1}$. The absence of the amide group absorption in the FTIR spectra may be due to the linkage between $\mathrm{FeO}$ and $\mathrm{N}$ of amide group.

Previously it was reported that the characteristic absorption bands of Fe-O bond of bulk ${ }^{16}$ $\mathrm{Fe}_{3} \mathrm{O}_{4}$ is $570 \mathrm{~cm}^{-1}$. However in this case, the band is shifted to high wavenumbers of about $682 \mathrm{~cm}^{-1}$. This phenomenon can be explained according to the formation of Fe-O-N bonds, where $\mathrm{Fe}-\mathrm{O}-\mathrm{H}$ groups on the surface of $\mathrm{Fe}_{3} \mathrm{O}_{4}$ particles are replaced by $\mathrm{Fe}-\mathrm{O}-\mathrm{N}$. More electronegativity of $\mathrm{N}$ than $\mathrm{H}$ leads to the enhancement of bond force constant for $\mathrm{FeO}$ bonds ${ }^{17}$. So the absorption bands are shifted to higher wave numbers. Based on these observations, it is clear that aniline and acrylamide were polymerized on to the surface of $\mathrm{Fe}_{3} \mathrm{O}_{4}$ by free radical polymerization.

Since there are large surface-volume atomic ratio, high surface activity and amount of dangling bonds on nanoparticles surface, the atoms on the surface are apt to absorb ions or molecules in the solution ${ }^{18}$. When $\mathrm{Fe}_{3} \mathrm{O}_{4}$ nanoparticles were dispersed in a neutral aqueous solution, the bare atoms of $\mathrm{Fe}$ and $\mathrm{O}$ on the particle surface would absorb $\mathrm{OH}^{-}$and $\mathrm{H}^{+}$ respectively, so that there is $\mathrm{OH}$ - rich surface. Hence the $\mathrm{OH}$ on the surface can react with PAni through the anilinium ion. Therefore the nanoparticles can be coated with PAni molecules by chemical bond. 


\section{Particle analyzer}

Particle size analyzer determines the distribution of average diameter of the grains or particles in a sample. The particle size distributionsof PAni-PAAm $/ \mathrm{Fe}_{3} \mathrm{O}_{4}$ nanoparticles recorded using nanoparticle analyzer is shown in Figure 2. The average diameter of the PAni-PAAm/ $/ \mathrm{Fe}_{3} \mathrm{O}_{4}$ lies in the range of 300-600 nm and the average diameter was found to be $415 \mathrm{~nm}$.

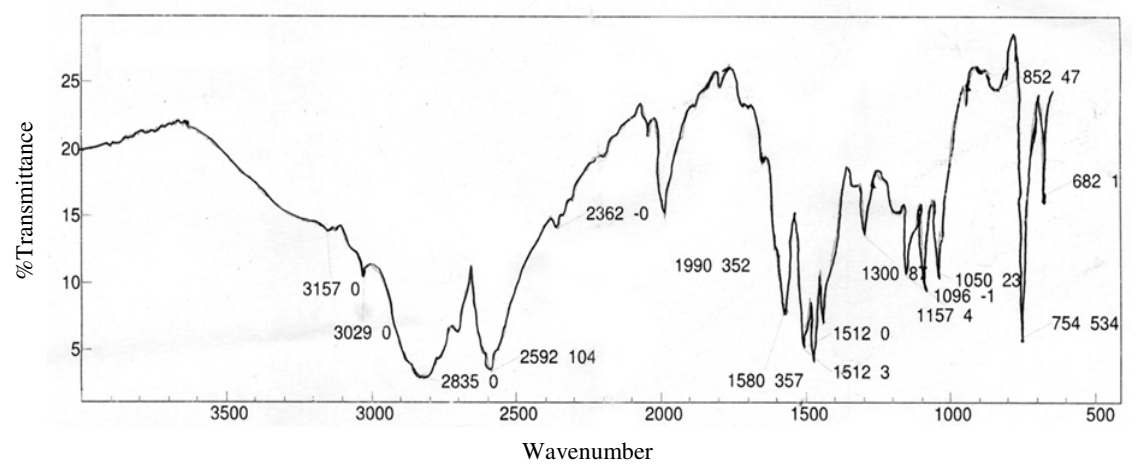

Figure 1. FTIR spectrum of PAni-PAAm/ $/ \mathrm{Fe}_{3} \mathrm{O}_{4}$

\section{Weight loss studies}

\section{Corrosion protection efficiency as a function of time}

The corrosion protection efficiency of the PAni-PAAm $/ \mathrm{Fe}_{3} \mathrm{O}_{4}$ as determined by weight loss method at room temperature is depicted in the Table 1. From the Figures 2 and 3 we could envisage the increase in corrosion rate when immersion period is increased. But still the increase in concentration of the polymer inhibitor decreases the corrosion rate and a maximum efficiency is achieved with $100 \mathrm{ppm}$ or $200 \mathrm{ppm}$ concentration for most of the studies. This phenomenon is due to adsorption of inhibitor molecules on the metal surface which will be explained using the adsorption isotherm (Figure 4) of the inhibitor.

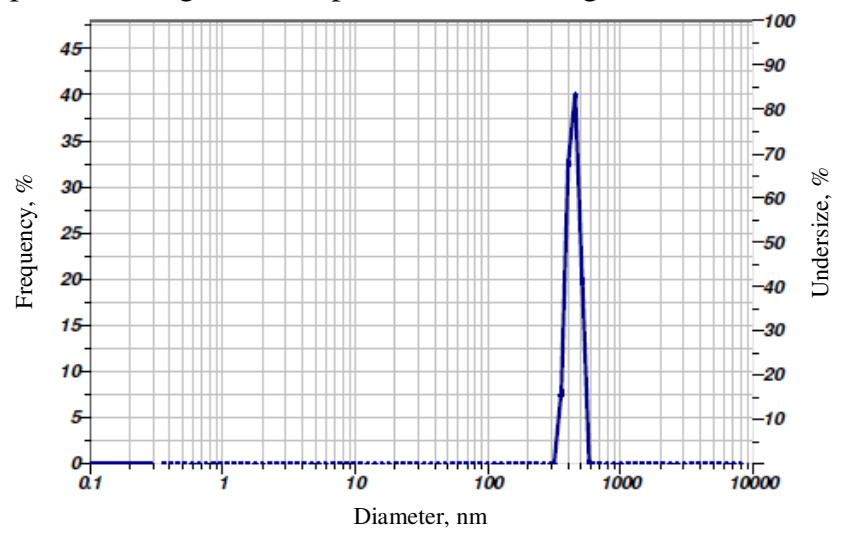

Calculation results

\begin{tabular}{ccccc}
\hline Peak No & S.P.Area ratio & Mean & S $>$ D. & Mode \\
\hline 1 & 1.00 & $415.7 \mathrm{~nm}$ & $43.6 \mathrm{~nm}$ & $419.4 \mathrm{~nm}$ \\
2 & ---- & ---- & ---- & --- \\
3 & ---- & ---- & --- & --- \\
Total & 1.00 & $415.7 \mathrm{~nm}$ & $43.6 \mathrm{~nm}$ & $419.4 \mathrm{~nm}$ \\
\hline
\end{tabular}

Figure 2. Particle size distribution graph ofPAni-PAAm/ $/ \mathrm{Fe}_{3} \mathrm{O}_{4}$ nanoparticles 


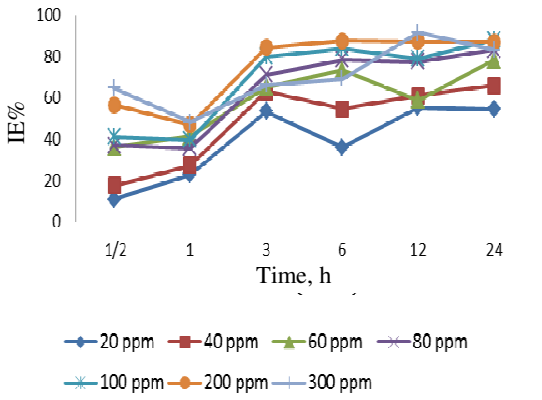

Figure 3. IE as a function of time

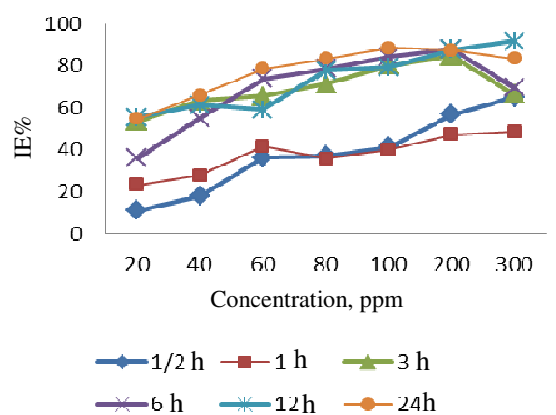

Figure 4. IE as a function of concentration

\section{Adsorption characteristics of $\mathrm{PAni}-\mathrm{PAAm} / \mathrm{Fe}_{3} \mathrm{O}_{4}$ nanocomposite}

Adsorption isotherms are usually to describe the nature of the adsorption of the inhibitor on the metal surface. The most frequently used isotherms include Langmuir, Temkin, Frumkin, Hill deBoer, Parsons, Flory-Huggins, Dhar-Flory Huggins, Bockris-Swinkles and thermodynamic/kinetic model of El-Awady et al. ${ }^{19-21}$. Among these isotherms, Langmuir provided the best fit with the experimental data retrieved from weight loss studies conducted at room temperature. Langmuir adsorption isotherm was plotted by taking concentration $(C)$ of the inhibitor in $\mathrm{X}$-axis and $C / \theta$ in $\mathrm{Y}$-axis. The regression coefficients $\left(R^{2}\right)$ listed in Table 1 , are almost equal to 1 , which show that the experimental data fits the Langmuir isotherm.

Table 1. Corrosion rate and inhibition efficiency for various concentrations of PAni-PAAm/ $\mathrm{Fe}_{3} \mathrm{O}_{4}$ at various time intervals

\begin{tabular}{|c|c|c|c|c|c|c|c|c|c|c|c|c|c|}
\hline \multirow{3}{*}{$\begin{array}{c}\text { Conc. } \\
\text { ppm }\end{array}$} & \multicolumn{12}{|c|}{ Immersion time, $\mathrm{h}$} & \multirow{3}{*}{$\mathrm{R}^{2}$} \\
\hline & \multicolumn{2}{|c|}{$1 / 2$} & \multicolumn{2}{|c|}{1} & \multicolumn{2}{|c|}{3} & \multicolumn{2}{|c|}{6} & \multicolumn{2}{|c|}{12} & \multicolumn{2}{|c|}{24} & \\
\hline & CR & IE & $\mathrm{CR}$ & IE & $\mathrm{CR}$ & IE & CR & IE & CR & IE & $\mathrm{CR}$ & IE & \\
\hline Blank & 346 & & 355 & & 361 & & 436 & & 660 & & 1056 & & \\
\hline 20 & 308 & 11 & 273 & 23 & 168 & 53 & 279 & 36 & 294 & 55 & 482 & 54 & 0.94 \\
\hline 40 & 285 & 18 & 257 & 27 & 133 & 63 & 197 & 55 & 261 & 61 & 360 & 66 & 0.99 \\
\hline 60 & 221 & 36 & 207 & 41 & 125 & 65 & 115 & 74 & 271 & 59 & 228 & 78 & 0.97 \\
\hline 80 & 218 & 37 & 228 & 36 & 104 & 71 & 94 & 78 & 148 & 78 & 178 & 83 & 0.96 \\
\hline 100 & 204 & 41 & 214 & 40 & 72 & 80 & 70 & 84 & 137 & 79 & 125 & 88 & 0.99 \\
\hline 200 & 150 & 57 & 188 & 47 & 56 & 84 & 54 & 88 & 84 & 87 & 136 & 87 & 1 \\
\hline 300 & 122 & 65 & 183 & 48 & 122 & 66 & 134 & 69 & 56 & 91 & 177 & 83 & 0.94 \\
\hline
\end{tabular}

Corrosion protection efficiency as a function of temperature

The corrosion inhibition efficiencies of the PAni-PAAm/ $/ \mathrm{Fe}_{3} \mathrm{O}_{4}$ evaluated at different temperatures are presented in Table 2 and represented graphically in Figure 5. The increase in the corrosion rate with the temperature is subsided by the increase in the inhibitor concentration. This is attributed to the nature of adsorption between the inhibitor molecules and the metal surface.

\section{Thermodynamic parameters of the adsorption}

The nature of adsorption can be physical or chemical which can be determined from the thermodynamic functions of adsorption. The values of free energy for adsorption $\Delta G$ are calculated using the following formulae ${ }^{22}$. 
Table 2. Corrosion rate and IE for various concentrations of PAni-PAAm/ $\mathrm{Fe}_{3} \mathrm{O}_{4}$ at various temperatures

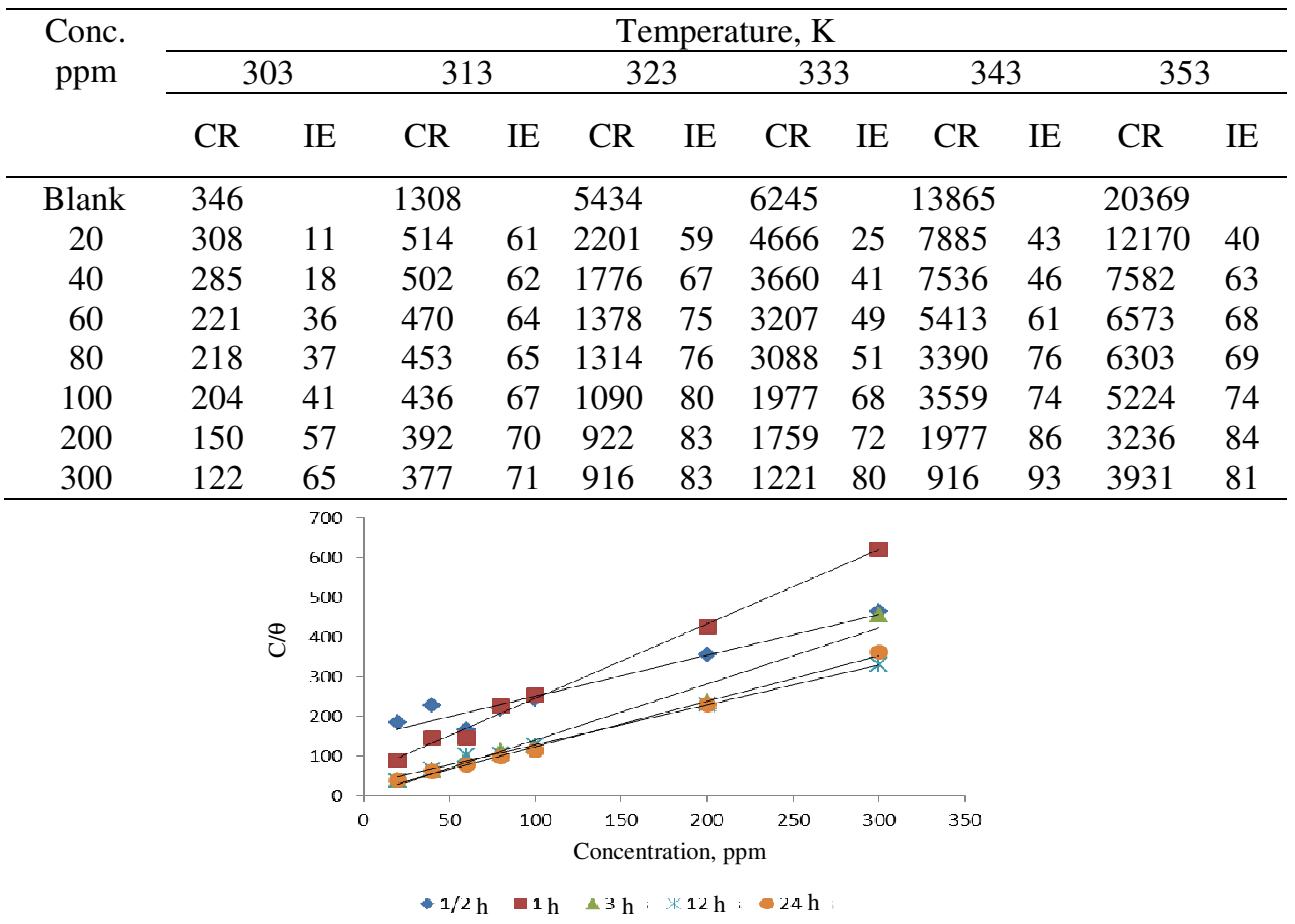

Figure 5. Langmuir isotherm model for mild steel in $1 \mathrm{M} \mathrm{HCl}$ containing PAni-PAAm/ $\mathrm{Fe}_{3} \mathrm{O}_{4}$

$$
\begin{aligned}
& \log C=\log \left(\frac{\theta}{1-\theta}\right)-\log B \\
& \log B=-1.74-\frac{\Delta G^{0} a d s}{2.303 R T}
\end{aligned}
$$

Where $\theta$ is the surface coverage, $R$ is $8.314 \mathrm{~J} / \mathrm{K}$ and $T$ is temperature in $\mathrm{Kmol}^{-1}$. Inspection of the values of thermodynamic parameters listed in Table 3 draws the following conclusions:

Table 3. Thermodynamic parameters of adsorption of PAni-PAAm/ $\mathrm{Fe}_{3} \mathrm{O}_{4}$ on mild steel

\begin{tabular}{|c|c|c|c|c|c|c|c|c|c|c|}
\hline \multirow{2}{*}{$\dot{B}_{\text {in }}$} & \multirow{2}{*}{$\begin{array}{c}\text { Conc. } \\
\text { ppm }\end{array}$} & \multirow{2}{*}{$\begin{array}{c}E a \\
\mathrm{~kJ} / \\
\mathrm{mole}\end{array}$} & \multicolumn{6}{|c|}{$\Delta G, \mathrm{~kJ} /$ mole } & \multirow{2}{*}{$\begin{array}{c}\text { Change in } \\
\text { enthalpy } \\
(\Delta H) \\
\mathrm{kJ} / \text { mole }\end{array}$} & \multirow{2}{*}{$\begin{array}{c}\text { Change in } \\
\text { entropy } \\
(\Delta S) \\
\mathrm{J} / \mathrm{K}\end{array}$} \\
\hline & & & 303 & 313 & 323 & 333 & 343 & 353 & & \\
\hline 1 & Blank & 71.0 & - & - & - & - & - & - & - & - \\
\hline 2 & 20 & 70.0 & -23 & -17 & -18 & -22 & -21 & -22 & -11.17 & -0.028 \\
\hline 3 & 40 & 64.8 & -23 & -19 & -19 & -22 & -22 & -21 & -17.72 & -0.010 \\
\hline 4 & 60 & 64.5 & -22 & -20 & -19 & -23 & -22 & -22 & -12.61 & -0.026 \\
\hline 5 & 80 & 60.9 & -22 & -20 & -19 & -23 & -21 & -22 & -17.69 & -0.011 \\
\hline 6 & 100 & 59.2 & -23 & -21 & -19 & -22 & -22 & -22 & -18.22 & -0.010 \\
\hline 7 & 200 & 53.7 & -23 & -22 & -21 & -23 & -21 & -22 & -22.99 & 0.003 \\
\hline 8 & 300 & 52.1 & -23 & -23 & -22 & -23 & -20 & -24 & -22.49 & 0.002 \\
\hline
\end{tabular}
surface in $1 \mathrm{M} \mathrm{HCl}$ 
The negative values of $\Delta G_{\text {ads }}$ ensure the spontaneity of the adsorption process and stability of the layer on mild steel surface. Generally the values of $\Delta G$ around $-20 \mathrm{~kJ} \mathrm{~mol}^{-1}$ or lower are consistent with electrostatic interaction between the charged molecules and the charged metal (Physisorption), those around $-40 \mathrm{KJ} \mathrm{mol}^{-1}$ or higher involve charge sharing or transfer from inhibitor molecules to the metal surface to form a coordinate type of bond (Chemisorption) $^{22,23}$.

In this case, the values of free energy of adsorption $\Delta G_{\mathrm{ads}}$ lie in between -24 to $-18 \mathrm{~kJ}$, which represents the spontaneous physical nature of the adsorption ${ }^{24}$. The nature of the adsorption is enhanced by means of $\mathrm{Fe}_{3} \mathrm{O}_{4}$ nanoparticles combined with lone pair of electrons on $\mathrm{N}, \mathrm{O}$ and pi electrons of polyaniline ring, which actually is responsible for electrostatic adsorption of the inhibitor on mild steel surface.

The enthalpy of adsorption and entropy of adsorption are calculated from the intercept and slope of the plot constructed by taking temperature in the $\mathrm{X}$-axis and $\Delta G_{\text {ads }}$ values in the Y-axis for various concentrations. The negative values of enthalpy of adsorption ensure the adsorption of inhibitor molecules on the mild steel is an exothermic process ${ }^{25}$. Since the values of enthalpy of adsorption are less than $40 \mathrm{~kJ} \mathrm{~mol}^{-}$ ${ }^{1}$, the adsorption is a physisorption ${ }^{26-28}$. The entropy of adsorption $\Delta S_{\text {ads }}$ increases with increasing concentration of the inhibitor, because there is an increase in the disorderliness on going from the reactant to activated complex. Sudhish et al. ${ }^{29}$ describes this phenomenon as follows: In the free acid solution, the transition state of the rate determining recombination step represents a more orderly arrangement relative to the initial state, so a negative value of entropy is obtained. In the presence of the inhibitor, however the rate determining step is the discharge of the hydrogen ions, but the surface of the metal is covered by inhibitor molecules which in turn retards the discharge of hydrogen ions causing the system to pass from a random arrangement.

The activation energy $E a$ for adsorption is calculated using from the slope of the isotherm plotted with $\log$ corrosion rate $v s .1 / T * 10^{3}$, using the following formula

$$
E a=-2.303 \times \mathrm{R} \times \text { Slope of the isotherm }
$$

The decrease in the activation energy of adsorption $E a$ with increasing concentration of the inhibitor obviously indicates the ease of adsorption of inhibitor on the metal surface.

\section{Thermodynamic parameters for the metal dissolution process}

In order to monitor the corrosion process, thermodynamic parameters for the metal dissolution process during the corrosion was calculated and presented in the Table 5. The temperature effect during corrosion inhibition process was assessed by performing experiments at 303-353 $\mathrm{K}$ in $1 \mathrm{M} \mathrm{HCl}$ containing different concentrations of PAni-PAAm/ $/ \mathrm{Fe}_{3} \mathrm{O}_{4}$. The activation energy for the metal dissolution process was calculated using the following Arrhenius equation ${ }^{30,31}$.

$$
\log (C r)=\frac{-E a}{2.303 R T}+\log _{\lambda}
$$

Where $E a$ is the activation energy, $R$ is the molar gas constant and $\lambda$ is the Arrhenius pre-exponential factor.

A plot of $\log \left(C_{R} / T\right)$ versus $1 / T$ gives the slope $(-\Delta H / 2.303 \mathrm{R})$ and the intercept $[\log$ $(R / N h)+(\Delta S / 2.303 R)]^{32,33}$, from which the $\Delta H$ and $\Delta S$ were calculated and listed in the Table 4 . The values of activation energies are increasing with increase in concentration of the inhibitor which shows that the metal dissolution becomes difficult as the inhibitor concentration increases. Similarly the values of $\Delta G$ and $\Delta H$ and $\Delta S$ also increase with increasing concentration of the inhibitor. This may be attributed due to the presence of 
energy barrier for the reaction; that is adsorption of the inhibitor leads to rise in enthalpy and free energy. The negative values of the entropy imply that the activated complex in the rate determining step represents an association rather than a dissociation step, meaning that a decrease in disordering takes place on going from reactants to the activated comple $\mathrm{x}^{34}$. More the negativity of free energy and enthalpy, more is the spontaneity of the reaction. In this case the negativity of enthalpy and free energy are decreasing, thereby proving that the reaction of metal dissolution is becoming less spontaneous, or is slow when the inhibitor concentration is increased gradually when compared with the blank $\mathrm{HCl}$.

Table 4. Thermodynamic parameters of Mild steel dissolution in $1 \mathrm{M} \mathrm{HCl}$ containing various concentrations of PAni-PAAm/ $/ \mathrm{Fe}_{3} \mathrm{O}_{4}$

\begin{tabular}{|c|c|c|c|c|c|c|c|c|c|c|}
\hline \multirow{2}{*}{$\begin{array}{l}\dot{2} \\
\dot{z}\end{array}$} & \multirow{2}{*}{$\begin{array}{l}\text { Conc. } \\
\text { ppm }\end{array}$} & \multirow{2}{*}{$\begin{array}{c}\text { Activation } \\
\text { energy } \\
(E a) \\
\mathrm{kJ} / \text { mole }\end{array}$} & \multicolumn{6}{|c|}{$\begin{array}{c}-\Delta G, \\
\mathrm{~kJ} / \text { mole }\end{array}$} & \multirow{2}{*}{$\begin{array}{l}\text { Change in } \\
\text { enthalpy } \\
(\triangle H) \\
\mathrm{kJ} / \text { mole }\end{array}$} & \multirow{2}{*}{$\begin{array}{c}\text { Change in } \\
\text { entropy } \\
(\Delta S) \\
\mathrm{J} / \mathrm{K}\end{array}$} \\
\hline & & & 303 & 313 & 323 & 333 & 343 & 353 & & \\
\hline 1 & Blank & -71 & - & - & - & - & - & - & - & - \\
\hline 2 & 20 & -70 & -52 & -52 & -52 & -52 & -51 & -50 & -68.11 & -51.58 \\
\hline 3 & 40 & -65 & -52 & -51 & -50 & -51 & -49 & -49 & -66.62 & -52.05 \\
\hline 4 & 60 & -64 & -53 & -47 & -46 & -48 & -45 & -45 & -62.92 & -52.76 \\
\hline 5 & 80 & -61 & -53 & -44 & -44 & -46 & -43 & -42 & -60.32 & -53.20 \\
\hline 6 & 100 & -59 & -54 & -38 & -38 & -43 & -37 & -36 & -54.79 & -54.18 \\
\hline 7 & 200 & -54 & -54 & -39 & -39 & -43 & -38 & -37 & -55.79 & -54.00 \\
\hline 8 & 300 & -52 & -55 & -34 & -34 & -40 & -33 & -32 & -51.13 & -54.92 \\
\hline
\end{tabular}

\section{Electrochemical experiments}

\section{Potentiodynamic polarization measurements}

The effect of inhibitor concentration on anodic and cathodic curves of the mild steel was studied using potentiodynamic polarization technique. The results including Tafel slopes (ba and bc), corrosion current $\left(\mathrm{I}_{\text {corr }}\right)$, corrosion potential $\left(\mathrm{E}_{\text {corr }}\right)$ and inhibition efficiency calculated using the Eq. (8) are listed in Table 5 and the Tafel plot is shown in Figure 6.

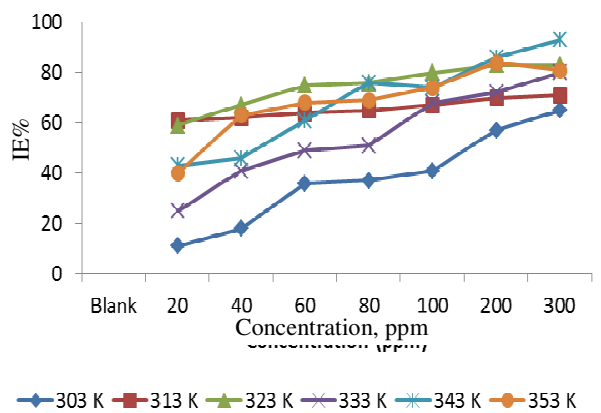

Figure 6. Corrosion protection efficiency as a function of temperature

$I_{\text {corr }}^{o}$ and $I_{\text {corr }}$ are the corrosion current densities of uninhibited and inhibited solutions respectively. From the Table 5, the values of the Tafel slopes are approximately constant and are independent of the inhibitor concentration. This behavior suggests that the inhibitor molecules affect the corrosion rate of mild steel without changing the metal dissolution ${ }^{35}$. $E_{c o r r}$ values do not change significantly in inhibited solution as compared to uninhibited solution, which means that this type of inhibitor is a mixed type inhibitor ${ }^{36} . I_{\text {corr }}$ value is the cathodic current density determined by the extrapolation of cathodic Tafel lines to the corrosion 
potential. In this case, $I_{\text {corr }}$ values decreased with increasing concentration thereby proving inhibiting efficiency of PAni-PAAm/ $/ \mathrm{Fe}_{3} \mathrm{O}_{4}$. This is because of the deposition of the inhibitor molecules of the mild steel which in turn forms a protective layer and prevents the interaction with the $\mathrm{HCl}$.

$$
I E(\%)=100 X\left[1-\frac{\text { Icorr }}{I^{o} \text { corr }}\right]
$$

Table 5. Electrochemical parameters of potendiodynamic polarization studies of mild steel in $1 \mathrm{M} \mathrm{HCl}$ containing various concentrations of PAni-PAAm/ $/ \mathrm{Fe}_{3} \mathrm{O}_{4}$

\begin{tabular}{|c|c|c|c|c|c|c|c|c|c|c|c|c|}
\hline $\begin{array}{l}\dot{0} \\
\dot{n}\end{array}$ & $\begin{array}{l}\Xi \\
\tilde{a} \\
\dot{0} \\
\tilde{0}\end{array}$ & $\begin{array}{l}\frac{0}{0} \\
\vdots \\
\Xi \\
0 \\
0\end{array}$ & 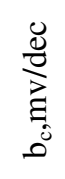 & 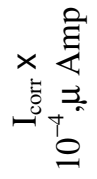 & 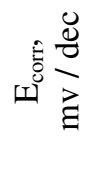 & $\begin{array}{l}\delta^{\circ} \\
\text { Il }\end{array}$ & 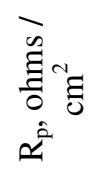 & $\begin{array}{l}\text { ठ0 } \\
\text { घิ }\end{array}$ & 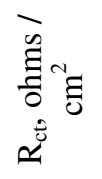 & $\begin{array}{l}\Delta \\
\Xi \\
\Xi\end{array}$ & 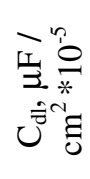 & $\begin{array}{l}\delta^{\circ} \\
0^{\circ}\end{array}$ \\
\hline 1 & 0 & 381 & 287 & 116 & -483 & & 7.633 & & 102.4 & & 39.89 & \\
\hline 2 & 40 & 326 & 349 & 101 & -491 & 13.3 & 11.73 & 34.97 & 116.7 & 12.1 & 25 & 0.375 \\
\hline 3 & 60 & 321 & 315 & 60 & -477 & 48.5 & 14.09 & 45.86 & 116.7 & 12.2 & 25 & 0.375 \\
\hline 4 & 100 & 284 & 174 & 33 & -475 & 71.2 & 19.22 & 60.30 & 149.8 & 31.6 & 19 & 0.525 \\
\hline 5 & 200 & 242 & 167 & 22 & -475 & 81.1 & 23.36 & 67.32 & 155.7 & 34.2 & 16 & 0.60 \\
\hline 6 & 300 & 246 & 208 & 23 & -468 & 79.8 & 22.2 & 65.61 & 132.0 & 22.4 & 26 & 0.35 \\
\hline
\end{tabular}

Inspection of Figure 7, shows that the addition of inhibitor affects both cathodic and anodic parts of the polarization curves. The presence of inhibitor caused an ennoblement of the corrosion potential of mild steel and the corresponding anodic and cathodic polarization curves gives rise to parallel Tafel lines indicating that the hydrogen evolution reaction is activation controlled and the addition of inhibitor did not modify the mechanism of the proton discharge reaction ${ }^{37}$. This concludes that the inhibitor is a mixed inhibitor affecting both cathodic and anodic processes.

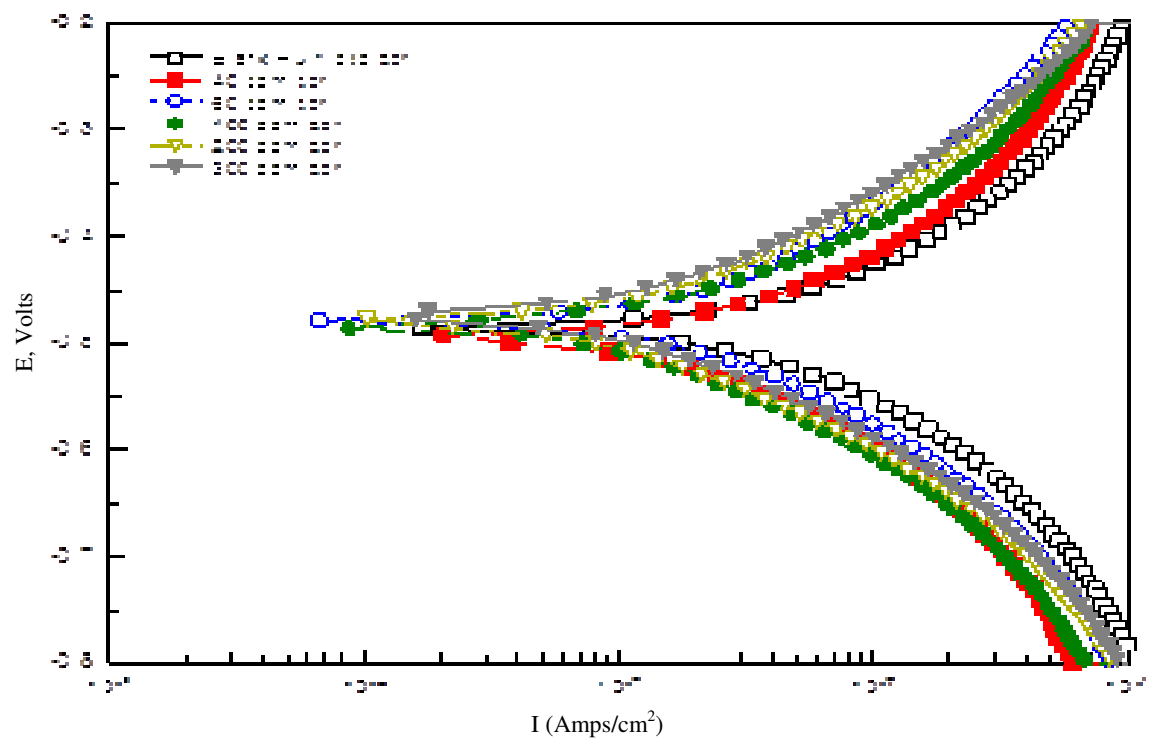

Figure 7. Potentiodynamic polarization curves for mild steel immersed in $1 \mathrm{M} \mathrm{HCl}$ containing various concentrations of PAni-PAAm $/ \mathrm{Fe}_{3} \mathrm{O}_{4}$ 


\section{Electrochemical impedance spectroscopy measurements}

An impedance measurement is a widely used tool for investigating corrosion inhibition process. It provides wealth of information on both the capacitive and resistive behavior at interface and hence enables the evaluation of performance of the tested inhibitor compounds. Figure 8 shows the impedance spectra in complex plane representation (Nyquist plot) recorded for mild steel electrode immersed in $1 \mathrm{M} \mathrm{HCl}$ at room temperature, in the presence of various concentrations of the inhibitor.

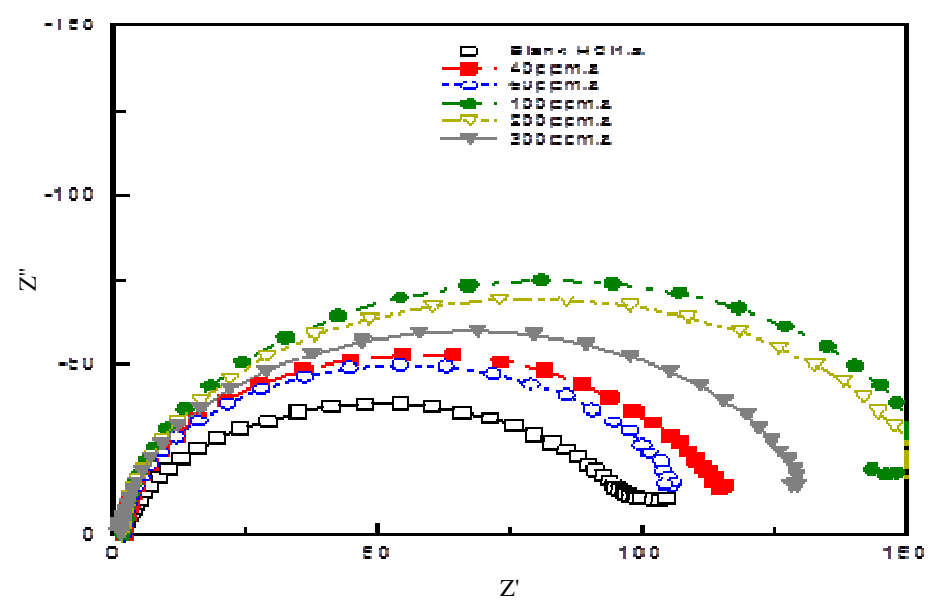

Figure 8. Nyquist plot for mild steel immersed in $1 \mathrm{M} \mathrm{HCl}$ containing various concentrations of PAni-PAAm/ $/ \mathrm{Fe}_{3} \mathrm{O}_{4}$

The inhibition efficiencies calculated using the polarization resistance (Rp) and charge transfer resistance (Rct) are listed in the Table 5. The inhibition efficiencies are calculated using the formula;

$$
I E(\%)=\frac{R c t-R c t^{o}}{R c t} ; \frac{R p-R p^{o}}{R p}
$$

Where $R c t$ and $R p$ are resistances of inhibited solutions and $R c t^{\circ}$ and $R p^{\circ}$ are resistances of uninhibited solutions. There is an increase in the $R p$ values and $R c t$ values with respect to the blank $\mathrm{HCl}$, which is an indication for the inhibitive action of the inhibitor by forming a protective film on the metal surface. A large charge transfer resistance is associated with slower corroding system ${ }^{38}$. The double layer capacitance $(\mathrm{Cdl})$ values decrease with increasing inhibitor concentration. This is attributed to the decrease in dielectric constant and/or increase in the thickness of the electrical double layer, which suggests the adsorption of inhibitor on the mild steel surface ${ }^{39}$.

The surface coverage $\theta$ is calculated with the $C d l$ values using the following formula, shows a maximum surface coverage at $200 \mathrm{ppm}$.

$$
\theta=\frac{c d l-c d l^{\circ}}{c d l}
$$

Where, $C d l$ and $C d l^{\circ}$ are double layer capacitance values of inhibited and uninhibited solutions. It is clear from the Figure 8 that the semicircles are not perfect and contains a large capacitive loop with the center under the real axis. Deviation from the perfect semicircle is known as frequency dispersion which occurs mainly due to surface roughness 
and inhomogeneity of the mild steel surface ${ }^{40}$. The shape of the capacitive loops suggests that the charge transfer controls the corrosion reaction of mild steel. In these cases of parallel network charge-transfer resistance, double layer capacitance is considered as a poor approximation $^{41}$.

\section{Mechanism of inhibition action of PAni-PAAm/Fe ${ }_{3} \mathrm{O}_{4}$ on mild steel}

From the experimental and theoretical results, we conclude that the plausible mechanism of corrosion inhibition of mild steel in $1 \mathrm{M} \mathrm{HCl}$ by PAni-PAAm/ $/ \mathrm{Fe}_{3} \mathrm{O}_{4}$ is based on adsorption. Inhibition efficiency depends on many factors ${ }^{42}$ which include the number of adsorption active centers in the molecule and their charge density, molecular size and mode of interaction with the metal surface. The steel surface gains a positive charge in the acid solution ${ }^{43}$ and chloride ions present in $\mathrm{HCl}$ forms an array on the metal surface. Since the PAni-PAAm $/ \mathrm{Fe}_{3} \mathrm{O}_{4}$ nanopolymer particles are protonated species, they could get adsorbed to the metal surface by means of electrostatic interaction with chloride ions.

\section{Conclusion}

The main conclusions derived from the study given below.

- Polyaniline-polyacrylamide/ $/ \mathrm{Fe}_{3} \mathrm{O}_{4}$ was synthesized and characterized using FTIR.

- The synthesized polymer was tested for its inhibitive action on mild steel in $1 \mathrm{M} \mathrm{HCl}$, and maximum inhibition efficiency was achieved with $100 \mathrm{ppm}$ and $200 \mathrm{ppm}$.

- The potentiodynamic polarization and impedance measurements correlated well with the weight loss studies.

\section{References}

1. Pencheng Huang, Shize Yang and Ganchang Zhou, J Appl Polym Sci., 1998, 69(3), 443-449.

2. Hossein Eisazadeh and Mohsen Ghorbani, J Vinyl Additive Technology, 2009, 15(3), 204-210.

3. Jeevananda T, Siddaramaiah S, Seetharamu S, Saravanan S and Lawrence D'Souza, Synthetic Metals, 2004, 140(2-3), 247-260.

4. Hossein Eisazadeh and Bahareh Ghobadi Bistouni, Korean J Chem Eng., 2011, 28(1), 287-292.

5. Mohsen Ghorbani and Hossein Eisazadeh, World Appl Sci J., 2008, 5(2), 204-210.

6. Hennig H, Rehorek A, Ackermann M, Rehorek D and Thomas Ph, Polymer composites, 2009, 30(1), 43-48.

7. Shailesh K Dhoke, Khanna A S and Jai Mangal Sinha T, Progress in Organic Coatings, 2009, 64(4), 371-382.

8. Radhakrishnan S, Siju C R, Debajyoti Mahanta, Satish Patil and Giridhar Madras, Electrochemicaacta, 2009, 54(4), 1249-1254.

9. Wang Y, Lim S, Luo J L and Xu Z H, Wear, 2006, 260(9-10), 976-983.

10. Bhanvase B A and Sonawane S H, Chem Engg J, 2010, 156(1), 177-183.

11. Davood Zaarei, Ali Asghar Sarabhi, Farhad Sharif and Seid Mahmood Kassiriha, $J$ Coat Technol Res., 2008, 5(2), 241-249.

12. Anwar Aglan, Aldinton Allie, Adriane Ludwick and Lawrence Coons, Surface Coat Technol., 2007, 202(2), 370-378.

13. Behsadnazab M, Mirabedni S M, Kabri K and Jamali S, Corros Sci., 2011, 53(1), 89-98.

14. Kakarla Raghava Reddy, Kwang-Pill Lee, Anantha Iyengar Gopalan and Ali Md Showkat, Polymers Advanced Technologies, 2007, 18(1), 38-43. 
15. Feng B, Honga R Y, Wu Y J, Liu G H, Zhong L H, Zheng Y, Ding J M and Wei D G, J Alloys Compounds, 2009, 473(1-3), 356-362.

16. Waldron R D, Phys Rev., 1955, 99(6), 1727-1735.

17. Wei W S, Yang J, Wang T J and Jin Yong, Acta Phys Chim Sin., 2001, 17(6), 507-510.

18. Ming Ma, Yu Zhang, Wei Yu, Hao-ying Shen, Hai-qian Zhang and Ning Gu, Colloids Surfaces A Physicochem Eng Aspects, 2003, 212(2-3), 219-226.

19. McCafferty E and Leidheiser Jr H, (Ed.), Corrosion control by coating, Sciece Press, Princeton, 1979.

20. Khamis E, Corrosion, 1990, 46, 476.

21. AbdEl-Rehim S S, Magdy A, Ibrahim A M and FKhaled K, J Appl Electrochem., 1999, 29(4), 593-599.

22. Donahue F M, and Nobe K, J Electrochem Soc., 1965, 112, 886-891.

23. Khamis E, Bellucci F, Latanision R M and El Ashry E S H, Corrosion, 1991, 47, 677.

24. Umoren S A, Eduok U M and Oguzie E E, Portugaliae Electrochemica Acta, 2008, 26(6), 533-546.

25. Umoren S A, Obot I B, Ebenso E E, Okafar P C, Ogbobe O and Oguzie E E, AntiCorros Meth Mater., 2006, 53(5), 277-282.

26. Li X H and Mu G N, Appl Surf Sci., 2005, 252(5), 1254-1265.

27. Badiea A M and Mohana K N, Corros Sci., 2009, 51(9), 2231-2241.

28. Martinez S and Stern I, Appl Surf Sci., 2002, 199(1-4), 83-89.

29. Sudhish K Shukla, Eno E. Ebenso, Int J Electrochem Sci., 2011, 6(8), 3277-3291.

30. Khedr M G A and Lashien A M S, Corros Sci., 1992, 33(1), 137-151.

31. Schorr M and Yahalom J, Corros Sci., 1972, 12(11), 867-868.

32. El Rehim S S A, Hassan H H and Amin M A, Mater Chem Phys., 2001, 70(1), 64-72.

33. Ebenso E E, Mater Chem Phys., 2003, 79(1), 58-70.

34. Sankarapapavinasam S and Ahmed M F, J Appl Electrochem., 1992, 22(12), 390-395.

35. Kaan C E and Mustafa H, Corros Sci., 2006, 48(4), 797-812.

36. Sykes J M, Br Corros J., 1990, 25, 175.

37. Lagrenee M, Mernari B, Chaibi N, Traisel M, Vezin H and Bentiss F, Corros Sci., 2001, 43(5), 951-962.

38. Khaled K F, Electrochem Acta, 2003, 48, 2493-2503.

39. Khaled K F, Appl Surf Sci., 2006, 252(12), 4120-4126.

40. Abd El-Rehim S S, Hassan H H and Amin M, Corros Sci., 2004, 46(5).

41. Popova A, Raicheva S R, Sokolova E, Christov M and Langmuir M, Corros Sci., 1996, 12, 1083-1089.

42. Fouda A S, El-Ewady Y A, Abo-El-Enien O M and Agizah F A, Anti Corros Method Mater., 2008, 55(6), 317-323.

43. Li Y, Zhao P, Liang Q and Hou B, Appl Surf Sci., 2005, 252(5), 1245-1253. 